\title{
Accessory renal artery associated with congenital kidney anomalies
}

\author{
Panneerselvam Sasikala, Sabita Singh \\ Department of Anatomy, Velammal Medical College, Madurai, Tamil Nadu, India
}

\begin{abstract}
Objectives: Common variations in the arterial supply of the kidney reflect the manner in which its vascularization changes during embryonic and early fetal life. The aim of the study was to determine the incidence of the accessory renal artery in association with congenital kidney anomalies.

Methods: The study was conducted on 37 dissected cadavers and 25 patients aged between 25-62 years who underwent renal CT angiography.

Results: Accessory renal artery associated with congenital kidney anomalies was observed in two cadavers: one had polycystic kidney disease with accessory renal artery in the right kidney, the second had malrotated kidney with accessory renal artery on the left kidney. Three cases in CT angiograms showed accessory renal artery with horseshoe kidney with three accessory renal arteries, pelvic kidney with accessory renal artery on the right side, and the third case had hypoplastic kidney with accessory renal artery on the right side.

Conclusion: Accessory renal artery can be due to the abnormal development of kidneys and variations in the positional anatomy of the kidney. This study supplements the presence of variations in renal arteries and its association with congenital kidney anomalies that are of clinical significance during diagnostic investigations and for avoiding complications during surgical approaches to the kidney.
\end{abstract}

Keywords: accessory renal artery; horseshoe kidney; malrotated kidney; polycystic kidney

Anatomy 2017;11(2):67-71 @2017 Turkish Society of Anatomy and Clinical Anatomy (TSACA)

\section{Introduction}

Renal arteries are a pair of lateral branches from the abdominal aorta at the level of L1-L2, little below the origin of the superior mesenteric artery. Each renal artery divides into an anterior and a posterior division near the hilum of the kidney, which in turn divides into five segmental arteries supplying the different renal vascular segments. ${ }^{[1]}$ Variations in the number, source and course of the renal arteries are common, most common variation being the accessory renal artery. ${ }^{[2]}$ Variations in the kidney arterial supply reflect the manner in which the vascular supply continually changes during embryonic and early fetal life. Accessory renal arteries usually arise from the abdominal aorta above and below the main renal artery and follow it to the renal hilum. They are regarded as persistent embryonic lateral splanchnic arteries. ${ }^{[1]}$ The frequency of accessory renal arteries varies from $9 \%$ to $76 \%$ with an average of $30 \%$. In rare cases, accessory renal arteries may arise from the celiac trunk, superior mesenteric, inferior mesenteric, common iliac, middle sacral, or external iliac arteries. ${ }^{[3]}$

Accessory renal arteries arise as result of the complicated development of kidneys and variations in their positional anatomy. ${ }^{[4]}$ They can be derived from the internal spermatic, superior mesenteric, common iliac, hypogastric or middle sacral arteries, and may be associated with ectopic or fused kidneys. ${ }^{[5]}$ Accessory renal arteries are end arteries; therefore if they are damaged, the part of kidney supplied by it becomes ischemic. ${ }^{[6]}$ The knowledge of the variation of renal arteries and associated congenital renal anomalies is very much essential for medical educators, surgeons and radiologists for proper diagnosis and management of the patient. Thus, this study aimed to widen 


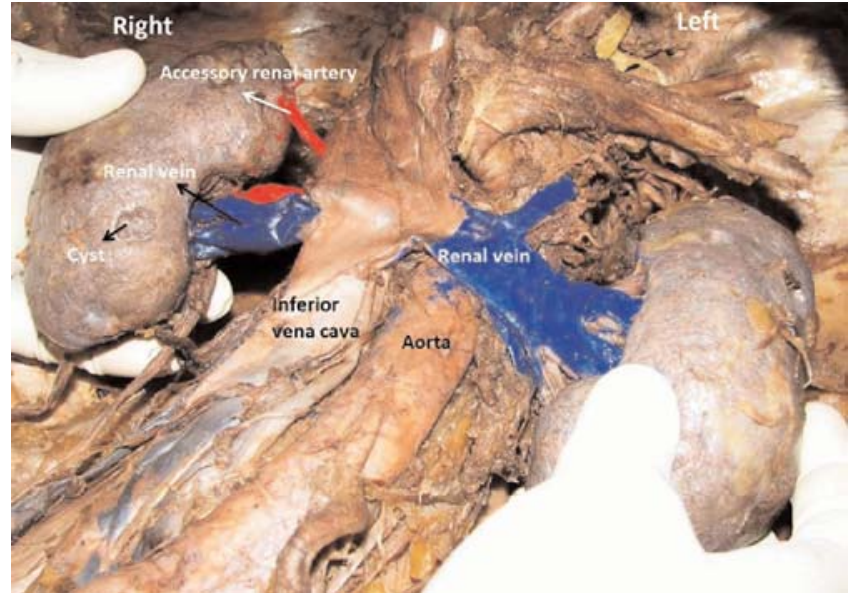

Figure 1. Polycystic kidney with accessory renal artery on the right side. [Color figure can be viewed in the online issue, which is available at www. anatomy.org.tr]

our knowledge about vascularization of the kidney, the incidence of accessory renal artery and its association with congenital anomalies of the kidney.

\section{Materials and Methods}

The present study was conducted on 37 dissected cadavers (31 males and 6 females) during routine dissection of the abdomen for medical undergraduate training in the Departments of Anatomy of Sri Ramachandra Medical College and Research Institute and the Chennai and Velammal Medical College, Madurai, India. This study also included 25 patients (16 males and 9 females) ranged between 25-62 years who underwent renal CT angiography in the Radiology and Imaging Sciences of Sri Ramachandra Medical College and Research Institute with due consent from the patients. The device used was a 64 Slice VCT xt high speed advantage scanner, Helical computed tomography (General Electric Medical Systems, Milwaukee, USA.)

Exposure of the kidney was done following the proper procedures in accordance with ethical standards of handling of cadavers for learning and teaching. Accessory renal arteries with associated congenital anomalies were examined in detail and photographed. The patients were informed about the angiographic procedures and probable complications were also explained to the patients. In this study, no additional interventions were performed on the patients. Ethics approval was received from the Institutional Ethics Committee of Sri Ramachandra University.

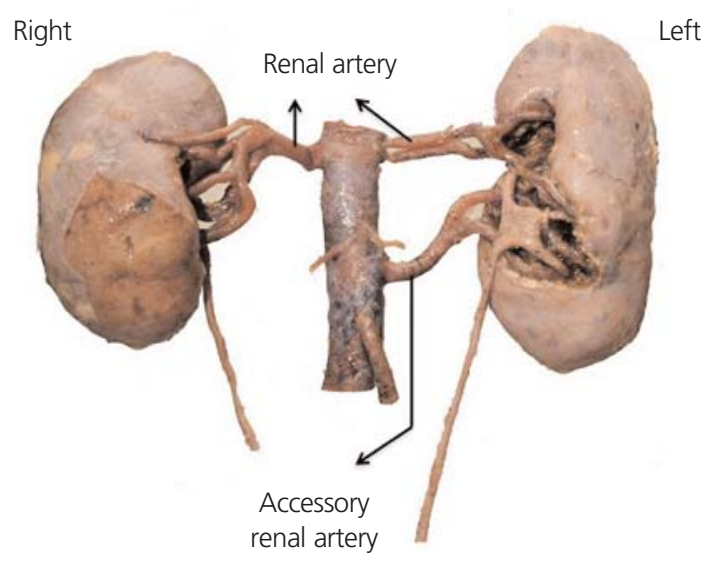

Figure 2. Malrotated kidney with accessory renal artery on the left side. [Color figure can be viewed in the online issue, which is available at www. anatomy.org.tr]

\section{Results}

Accessory renal artery associated with congenital anomalies was found in two cadavers and three CT angiograms. Of the two cadavers with accessory renal artery, one had polycystic kidney disease with accessory renal artery to the right kidney (Figure 1), and another had malrotated kidney with accessory renal artery on the left side (Figure 2). Three cases in CT angiograms showed accessory renal artery with various congenital anomalies. Horseshoe kidney (Figure 3) with three accessory renal arteries - one

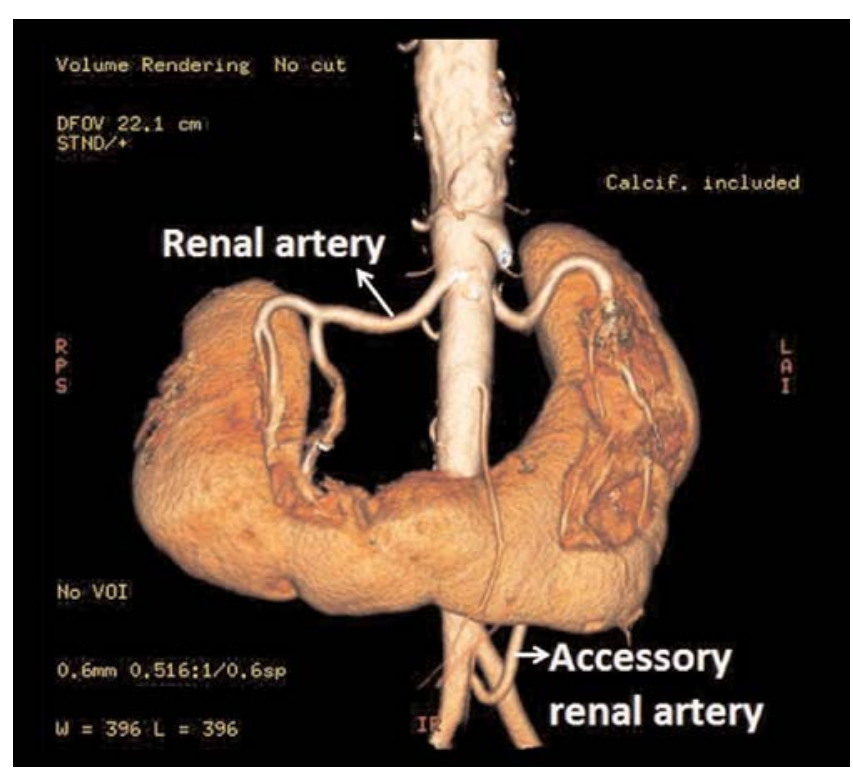

Figure 3. Horseshoe kidney with accessory renal artery on the left side. [Color figure can be viewed in the online issue, which is available at www. anatomy.org.tr] 
from right common iliac artery and two from abdominal aorta - was found in the first case. The second case had pelvic kidney with accessory renal artery on the right side. The third case had hypoplastic kidney with accessory renal artery on the right side.

The incidence of the accessory renal artery and asscociated kidney anomalies in cadaver specimens and patients who underwent renal CT angiography are shown in Table $\mathbf{1 .}$

\section{Discussion}

Knowledge of the variations of the renal artery and associated congenital anomalies is essential for exploring and managing renal trauma, renal transplantation, renovascular hypertension, renal artery embolization, angioplasty and vascular reconstruction for congenital and acquired lesions. ${ }^{[7]}$ It is essential to know the embryology of the renal artery and structural development of the kidney to understand the multitude of anomalies that may occur. The complex development of the kidneys through pronephros, mesonephros and metanephros, and the ascent of the kidney from the pelvis to the lumbar region, its vertical rotation and simultaneous acquisition of a vascular supply explain the common variations in the blood supply of kidneys associated with congenital malformations. ${ }^{[6]}$ The majority of renal artery variations are due to the changing position of the kidney, as a part of its normal development and ascent ${ }^{[8]}$ Kidneys develop from the intermediate mesoderm in the pelvic region. Later, they ascend to the adult position in the lumbar region. In the pelvic region, kidneys are supplied by branches of the internal iliac artery or the common iliac artery. The arterial supply shifts from the common iliac to the abdominal aorta with its ascent. In the ninth week of the intrauterine life, the kidneys come in contact with the suprarenal glands and the ascent ceases. This relative ascent results mainly from the growth of the embryo's body caudal to the kidneys. In effect, the caudal part of the embryo grows away from the kidneys so that they progressively occupy more cranial levels. The kidneys receive their most cranial branches from the abdominal aorta. These are the permanent renal arteries. Failure in degeneration of the initial branches leads to formation of accessory renal artery. Initially, the hilum of the kidney where vessels and nerves enter and leave faces ventrally; however, as the kidney relocates (ascends), it rotates medially by almost $90^{\circ}$. By the ninth week, the hilum is directed anteromedially. ${ }^{[9]}$ Nino-Murcia et al., are of the opinion that renal rotation takes place before definitive vascularization. This process occurs between 38 and 49 days of development, during the ascent of the kidney. The developing metanephros rotates from the dorsome-
Table 1

Incidence of the accessory renal artery and asscociated kidney anomalies in cadaver specimens and patients who underwent renal $\mathrm{CT}$ angiography.

\begin{tabular}{lcc}
\hline Groups & $\begin{array}{c}\text { Number of } \\
\text { kidneys }\end{array}$ & $\begin{array}{c}\text { Presence of associated } \\
\text { kidney anomaly }\end{array}$ \\
\hline Cadaver specimens & $5 / 37(13.5 \%)$ & $2 / 37(5.4 \%)$ \\
Renal CT angiography cases & $8 / 25(32 \%)$ & $3 / 25(12 \%)$ \\
\hline
\end{tabular}

dial to a more lateral position, relative to the collecting system, resulting in the hilum of kidney eventually rotating from the anterior to the medial position. In nonrotation, the renal pelvis presents itself ventrally in relation to the kidney mass. In incomplete rotation, it presents itself ventromedially. ${ }^{[10]}$

The kidney may become ectopic in the pelvis, if it fails to ascend adequately. The horseshoe kidney may be developed if the lower pole is fused and becomes trapped by the inferior mesenteric artery, and thus the kidney cannot ascend to the lumbar region. ${ }^{[1]}$

According to Felix, ${ }^{[12]}$ there are nine pairs of lateral mesonephric arteries arising from the dorsal aorta, arranged as cranial (1st and 2nd pair), middle (3rd and 4th pair) and caudal (6th to 9th pair) groups in $18 \mathrm{~mm}$ fetus. Renal artery develops from one pair of middle group. The persistence of more than one artery from the middle group results in formation of an accessory renal artery. Thus, the accessory renal arteries in our study are a result of persisting lateral mesonephric arteries from the middle group.

Varieties of congenital renal anomalies with accessory renal artery have been documented in literature so far. Accessory renal artery with unilateral congenital anomalies is more common than bilateral anomalies. Aberrant renal artery with unilateral anomaly was reported in $15 \%$ and bilateral anomaly in $5 \%$ specimens by Dhar and Lal. ${ }^{[13]}$

Accessory renal artery can delay the kidney migration that results in ectopic kidney or vice versa. The incidence of ectopic kidney with unilateral or bilateral accessary renal artery is about 1:500 to 1:110. The ectopic kidney can be unilateral or bilateral at various levels. Unilateral pelvic kidney was observed in 1:3000 and thoracic kidney in 1:13,000. Most of the cases of ectopic kidneys are asymptomatic. ${ }^{[14,15]}$ The present study reported unilateral pelvic kidney with accessory renal artery in one out of 25 cases in CT angiograms.

Polycystic kidney disease is one of the life-threatening inherited disorders. For many years, it was thought that the cysts were the result of failure of the metanephric 
diverticulum derivatives to join the tubules derived from the metanephrogenic blastema. It is now believed that the cystic structures are wide dilations of parts of the otherwise continuous nephrons, particularly the nephron loops (loops of Henle). ${ }^{[9]}$ Polycystic kidney can be observed in association with accessory renal artery. Manpreet et al. ${ }^{[16]}$ reported a case of left kidney with multiple cysts and accessory renal artery in right kidney. Both of these can cause renal failure, hypertension, hydronephrosis and even failure of renal transplants. We found multiple cysts in one out five cadavers who had accessory renal arteries.

Kidney rotates through $90^{\circ}$ ventromedially during its normal development. However, according to Bauer, ${ }^{[17]}$ the ureteral branching induces differentiation of the metanephric tissue, different degrees of unequal branching result in various forms of malrotation. Felix postulated that rotation is a result of unequal and different branching pattern of successive orders of ureteral tree. With excessive ventral branching more parenchyma develops ventrally and the renal pelvis seems to rotate medially. ${ }^{[12]}$ There are various types of renal anomalies related to abnormal rotation like nonrotation, incomplete rotation, excessive rotation or reverse rotation. Renal pelvis position depends on the types of rotation of the kidney. In non-rotation, renal pelvis is present ventrally, in incomplete rotation ventromedially, whereas in reverse rotation ventrolaterally. ${ }^{[18]}$ Our case is most probably unrotated kidney, since the pelvis is present ventrally .

Banerjee et al. ${ }^{[8]}$ reported an incompletely rotated kidney with three accessory renal vessels, two renal arteries, and one renal vein at the lower pole in left kidney. Ramteerthankar et al. ${ }^{[19]}$ found bilateral unrotation of the kidneys in a female cadaver without any associated variation. Atasever et al. ${ }^{[2]}$ observedan unrotated left kidney with partly extrarenal calyces associated with an accessory renal artery in a male cadaver.

As the renal rudiments ascend from the pelvic region to the loin, they remain entirely separate. If they come in contact and adhere, usually at the lower poles, this results in horseshoe kidney. ${ }^{[2]]}$ The incidence of horseshoe kidney is less than $0.3 \%$, in one out of 300 pyelographies. ${ }^{[22]}$ Mohanty et al., ${ }^{[23]}$ in a case report, observed a horseshoe kidney in a female cadaver, with extrarenal calyces, with two small caliber renal arteries supplying the upper segment of the organ on either side and a single accessory renal artery originating from the aorta on the right side and branching to supply the right and left middle segments together with a well-developed connecting bridge. Vaniya et al. ${ }^{[24]}$ noticed in a male cadaver, a horseshoe kidney with multiple renal arteries and extrarenal calyces. A horseshoe kidney may be problematic in abdominal aneurysm surgery, as the renal arteries arise normally only in $20 \%$ of these cases. ${ }^{[24]}$ In the present study, we observed a horseshoe shaped kidney with three accessory renal arteries, but no extrarenal calyces.

The frequency of unilateral hypoplastic kidney was reported to be one in 500 autopsies. The cause of hypoplastic kidney can be congenital or as a result of pyelonephritic shrinkage or as a combination of both. ${ }^{[25]}$ Guang-Qian Xiao et al. ${ }^{[26]}$ reported a case of unilateral hypoplastic kidney in a 33 year old male patient. We found one hypoplastic kidney with accessory renal artery in the right kidney among eight cases with accessory artery in CT angiograms.

Advances in surgical and uroradiological techniques dictate a reappraisal and definition of renal artery variations. The present study revealed the percentage of accessory renal arteries and its association with congenital anomalies using cadaver dissection and CT angiography techniques. This study will supplement the knowledge of variation in renal arteries and its association with congenital anomalies for avoiding complications during diagnostic investigations or surgical approaches to the kidney. The renal arteries can not be evaluated properly only by axial images, because they usually have a tortuous and variable course. Therefore, there is a need for additional views by CT angiography. ${ }^{[8]}$ Modification of CT protocol by generating thinner sections may improve the detection of accessory arteries. This information is exceedingly important to the surgeons in planning treatment strategies.

\section{References}

1. Bannister LH, Berus MM, Collins P, Dyson M, Dusek JE, Ferguson MWJ. Gray's anatomy. 40th ed. Edinburgh: Churchill Livingstone; 2008. p. 1225-33.

2. Bergman RA, Afifi AK, Miyauchi R. Illustrated encyclopedia of human anatomic variations: Opus II. Cardiovascular system: arteries: abdomen: renal arteries. http://www.anatomyatlases.org/Anatomic Variants/Cardiovascular/Text/Arteries/Renal.shtml [Retrieved April 7, 2010].

3. Hollinshead WH. Anatomy for surgeons. Volume 2. New York: Harper and Row; 1971. p. 533-46.

4. Bayramoglu A, Demiryurek D, Erbil KM. Bilateral additional renal arteries and an additional right renal vein associated with unrotated kidneys. Saudi Med J 2003;24:535-7.

5. Mcvay CB. Anson and Mcvay surgical anatomy. Volume 1. 6th ed. Philadelphia: W.B. Saunders; 1984. p. 739-43.

6. More Anju B, Hebbal GV, Rajesh S, Kunjumon PC. An unique asymmetrical bilateral variation of renal artery: right sided early division and left sided accessory/additional arteries. International Journal of Anatomy and Research 2014;2:583-8.

7. Cicekcibasi AE, Salbacak A, Seker M, Ziylan T, Buyukmumcu M, Tuncer I. An investigation of the origin, location, and variation of the renal arteries in human fetuses and their clinical relevance. Ann Anat 2005; 187:421-7. 
8. Banerjee SS, Paranjape, Arole V, Vatsalaswamy P. Variation of hilar anatomy in an incompletely rotated kidney associated with accessory renal vessels. Journal of Dr. D.Y. Patil University 2014;7:645-7.

9. Moore KL, Persaud TVN. Torchia MG. The developing human. Clinically oriented embryology. 9th ed. Philadelphia: Saunders; 2011. p. 249-50.

10. Nino-Murcia M, de Vries PA, Friedland GW. Congenital anomalies of the urinary tract. In: Pollack HM, McClennan BL, Dyer R, Kenny PJ, editors. Clinical urography. 2nd ed. Volume 1. Philadelphia: Saunders; 2000. p. 690-763.

11. Sadler TW. Langman's medical embryology. 12th ed. Philadelphia: Wolters Kluwer Health/Lippincott Williams and Wilkins; 2012. p. $238-40$.

12. Felix W. Mesonephric arteries (aa. mesonephricae). In: Kiebel F, Mall FP, editors. Manual of human embryology. Vol. 2. Philadelphia: Lippincott; 1912. p. 820-5.

13. Dhar P, Lal K. Main and accessory renal arteries-a morphological study. Ital J Anat Embryol 2005;110:101-10.

14. Zagyapan R, Pelin C, Kürkçüoğlu A. A retrospective study on multiple renal arteries in Turkish population. Anatomy 2009;3:35-9.

15. Zahoi DE, Miclauş G, Alexa A, Sztika D, Pusztai AM, Farca Ureche M. Ectopic kidney with malrotation and bilateral multiple arteries diagnosed using CT angiography. Rom J Morphol Embryol 2010;51:589-92.

16. Manpreet K, Sangeeta W, Anupama M. Anomalies by birth in urogenital system: clinical aspect. International Journal of Basic Science and Pharmacy 2012;2:39-41.

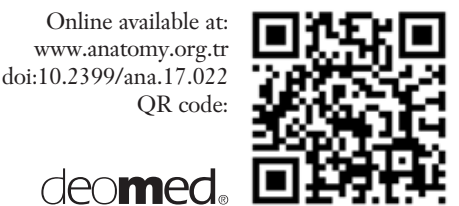

17. Bauer SB. Anomalies of the kidney and ureteropelvic junction. In: Walsh PC, Retik AB, editors. Campbell's urology. 7th ed. Philadelphia: Saunders; 1998. p. 1728-30.

18. Braasch WF. Anomalous renal rotation and associated anomalies. J Urol 1931;25:9-21.

19. Ramteerthankar RN, Joshi DS, Joshi RA, Pote AJ. Bilateral unrotation of kidneys. Saudi J Kidney Dis Transpl 2011;22:1033-4.

20. Atasever A, Hamdi Celik H, Durgun B, Yilmaz E. Unrotated left kidney with an accessory renal artery. J Anat 1992;181:507-8.

21. McGregor AL, Decker GAG, Du Plessis DJ. Lee McGregor's synopsis of surgical anatomy. 12th ed. Bristol: John Wright; 1986. p. 298-9.

22. Dees JE. Clinical importance of congenital anomalies of the upper urinary tract. J Urol 1941;46:659-66.

23. Mohanty C, Ray B, Samaratunga U, Singh G. Horseshoe kidney with extrarenal calyces - a case report. Journal of the Anatomical Society of India 2002;51:57-8.

24. Vaniya VH. Horseshoe kidney with multiple renal arteries and extrarenal calyces: a case report. Journal of the Anatomical Society of India 2004;53:52-4.

25. Bengtsson C, Hood B. The unilateral small kidney with special reference to the hypoplastic kidney. Review of the literature and authors' points of view. Int Urol Nephrol 1971;3:337-51.

26. Xiao GQ, Jerome JG, Wu G. Unilateral hypoplastic kidney and ureter associated with diverse mesonephric remnant hyperplasia. Am J Clin Exp Urol 2015;3:107-11.

\author{
Correspondence to: Sabita Singh, M.B; B.S, M.D \\ Department of Anatomy, Velammal Medical College, \\ Madurai, 625009, Tamil Nadu, India \\ Phone: +917667908292 \\ e-mail: drsabita1234@gmail.com \\ Conflict of interest statement: No conflicts declared.
}

This is an open access article distributed under the terms of the Creative Commons Attribution-NonCommercial-NoDerivs 3.0 Unported (CC BY-NCND3.0) Licence (http://creativecommons.org/licenses/by-nc-nd/3.0/) which permits unrestricted noncommercial use, distribution, and reproduction in any medium, provided the original work is properly cited. Please cite this article as: Sasikala P, Singh S. Accessory renal artery associated with congenital kidney anomalies. Anatomy 2017;11(2):67-71. 